\title{
Management of freezing rate and trehalose concentration to improve frozen dough properties and bread quality
}

\author{
Jesús E. GERARDO-RODRÍGUEZ ${ }^{1}$, Benjamín RAMÍREZ-WONG ${ }^{1 *}$, Ana I. LEDESMA-OSUNA ${ }^{1}$, \\ Concepción L. MEDINA-RODRÍGUEZ ${ }^{1}$, Refugio ORTEGA-RAMÍREZ ${ }^{1}$, María I. SILVAS-GARCÍA ${ }^{1}$
}

\begin{abstract}
Bread is one of the most consumed foods in the world, and alternatives have been sought to extend its shell life, and freezing is one of the most popular methods. The purpose of this study was to evaluate the effect of freezing rate and trehalose concentration on the fermentative and viscoelastic properties of dough and bread quality. Dough was prepared and trehalose was added at three concentrations $(0,400,800 \mathrm{ppm})$; dough was pre fermented and frozen at two freezing rates then stored for 42 days. Frozen dough samples were thawed every two weeks. $\mathrm{CO}_{2}$ production and elastic and viscous modulus were determined. In addition, bread was elaborated and specific volume and firmness were evaluated. High trehalose concentrations (400 and 800 ppm) produced dough with the best viscoelastic and fermentative properties. Greater bread volume and less firmness were observed when a slow freezing rate $\left(-.14^{\circ} \mathrm{C} / \mathrm{min}\right)$ was employed.
\end{abstract}

Keywords: frozen dough; trehalose; gluten viscoelasticity; bread quality.

Practical Application: Bread makers can benefit from this study to improve the quality of their products.

\section{Introduction}

Bread is one of the most highly consumed foods in the world at more than 9 billion kilograms per year (Cho \& Peterson, 2010), and the technology for bread manufacturing is probably one of the oldest. This technology has steadily evolved over the years; new materials, ingredients, and equipment have been introduced to produce better quality bread, and the baking industry is clearly benefiting from research on the improvement of industrial bread production (Selomulyo \& Zhou, 2007).

Recently, one of the most well studied methods for storing dough has been freezing, along with designing formulations that allow the production of good quality bread from frozen dough. However, this method has a number of disadvantages, such as ice crystal formation, loss of yeast bioavailability, and water redistribution. These factors change the functional properties of the dough and cause undesirable changes in proteins, dough viscoelasticity, crumb texture, and sensory properties, which leads to decreased bread quality (Casey \& Foy, 1995). Therefore, it is important to determine the most appropriate freezing rate for dough to attain comparable bread production to that obtained from fresh dough.

A visible quality parameter affected by storage at freezing temperatures is a decrease in bread volume due to the loss of gassing power of yeast and a decrease in the strength and stability of the gluten network, which reduces the ability to retain $\mathrm{CO}_{2}$ (Anon et al., 2004; Giannou et al., 2005). Gant et al.
(1990) observed that breaks in the gas cell membranes were attributed to mechanical damage of the gluten network caused by ice crystal formation.

Several approaches have been proposed to limit the damaging effects of freezing on dough, among which are the development and use of cryoresistent yeast strains (Tanghe et al., 2000) and recipes using ingredients and additives that function as cryoprotectants (trehalose) and hydrocolloids (Ribotta et al., 2004; Rouille et al., 2000). Trehalose is a nonreducing disaccharide composed of glucose molecules linked by alpha 1-1 glycosidic linkages. Trehalose does not participate in Maillard reactions and, therefore, has no influence on bread color and is not affected by the heat of the bread baking. Trehalose addition has not been extensively studied in frozen dough but has been successfully used as a cryoprotectant in foods such as fish, frozen tofu, jelly, and ice cream (Fuchigami et al., 2002). The mechanism of action of trehalose is based on its water absorption capacity, which in turn is due to its hydroxyl groups that confer hydrophilic properties. Furthermore, decreasing water diffusivity reduces the freezing point and protects yeast membranes from damage caused by freezing, osmotic dehydration, and denaturation (Diniz-Mendes et al., 1999; Karel \& Lund, 2003).

The objective of this study was to evaluate the effect of the freezing rate and trehalose content on the fermentative and viscoelastic properties of frozen dough and on bread quality. 


\section{Materials and methods}

\subsection{Raw materials}

Wheat flour was obtained by milling the Kronstad wheat cultivar. Fresh-pressed baker's yeast (Azteca S.A. of C.V., Guadalajara, México) was provided by MUNSA (Obregón, Sonora, México), and trehalose was provided by Hayashibara Co., Ltd. (Okayama, Japan). The other ingredients used include water, salt (Mar de Cortés, Sales del Valle S.A. de C.V.), and shortening (Inca, Alimentos Capullo, S. de R. L. C.V.), which were obtained at a local store in Hermosillo, Sonora, México.

\subsection{Flour characterization}

The following determinations were carried out on the wheat flour: moisture content (44-40 American Association of Cereal Chemists, 2000), ash content (08-03 American Association of Cereal Chemists, 2000), gluten content (38-11 American Association of Cereal Chemists, 2000), and sedimentation volume (56-61A American Association of Cereal Chemists, 2000). The nitrogen content was determined using a nitrogen determinator (Leco FP-528, St. Joseph, MI, USA), and the protein content was calculated from $\mathrm{N} \times 5.7$ (46-13 American Association of Cereal Chemists, 2000). Rheological properties were evaluated with a farinograph (Brabender Instruments, model 810143, South Hackensack, NJ, USA) (54-21 American Association of Cereal Chemists, 2000) and an alveograph (Chopin Instruments, Villeneuve-La-Garenne, France) (54-30 American Association of Cereal Chemists, 2000). All determinations were performed in triplicate.

\subsection{Dough preparation, freezing and storage}

Frozen dough used for French-type bread production was prepared using the following recipe: wheat flour (100\% baker's percentage), fresh-pressed yeast (Saccharomyces cerevisiae) (3\%), salt $(1.5 \%)$, shortening (5\%), and trehalose $(0,400$, or $800 \mathrm{ppm})$. Ingredients were weighed and mixed in a mixer (National MFG, Lincoln, NE, USA) for $1 \mathrm{~min}$. Yeast was added after the addition of salt to avoid contact between the two. Subsequently, water was added after the first min, and mixing continued for $3 \mathrm{~min}$. Water was added to a content of $60 \%$, as determined by a farinograph. The dough was divided into $50 \mathrm{~g}$ portions, then hand-molded (as with French-type bread) and pre-fermented in a proofing cabinet (National MFG, Lincoln, NE, USA) at $85 \%$ relative humidity (RH) and $30^{\circ} \mathrm{C}$ for $10 \mathrm{~min}$. Samples of pre-fermented dough were placed into airtight polyethylene bags. Each dough sample was frozen at a slow freezing rate $\left(-0.14^{\circ} \mathrm{C} / \mathrm{min}\right.$ for $\left.4 \mathrm{~h}\right)$ in a conventional freezer (Frigidaire, GLFC1526FW1, Aug., Canada) or at a fast freezing rate $\left(-1.75{ }^{\circ} \mathrm{C} / \mathrm{min}\right.$ for $\left.40 \mathrm{~min}\right)$ in an ultra-low temperature freezer (Thermo Scientific, ULT21866A, USA) up to $-20{ }^{\circ} \mathrm{C}$. The freezing rate was determined using a Thermopar which measure the core temperature of the sample, every minute was taken the temperature until $-20{ }^{\circ} \mathrm{C}$. Frozen dough samples prepared at both freezing rates were stored for $0,14,28$ or 42 days in a conventional freezer at $-20{ }^{\circ} \mathrm{C}$.

\subsection{Dough thawing and proofing}

Every 14 days, dough samples were thawed at $4{ }^{\circ} \mathrm{C}$ for $4 \mathrm{~h}$ and $15 \mathrm{~min}$ in a refrigerator (Whirlpool, ETI8NKXANO3, Whirlpool Co., Benton Harbor, MI, USA) and proofed in a proofing cabinet (National Meg. Co. Lincoln, NE, USA) at $85 \% \mathrm{RH}$ and $30^{\circ} \mathrm{C}$ for $50 \mathrm{~min}$. Then, the dough was immediately analyzed.

\subsection{Dough evaluation}

Fermentative test

The $\mathrm{CO}_{2}$ production was measured using a rheofermentograph (Chopin Rheo, type F3, Villeneuve-La-Garenne Cedex, France) by the procedure in the manual with modifications for $315 \mathrm{~g}$ of thawed dough. The test was performed in a hermetically sealed chamber in the movable basket of the gas meter with a $2-\mathrm{kg}$ cylindrical weight. The cover of the vat was equipped with an optical sensor. The test was conducted at $30^{\circ} \mathrm{C}$ for $3 \mathrm{~h}$. The tests were performed in duplicate.

\section{Viscoelasticity evaluation}

Fundamental rheological measurements of the dough were obtained through dynamic oscillation tests with a rheometer (Rheometrics Scientific, model RSF III, Piscataway, NJ, USA) equipped with parallel plates, $25 \mathrm{~mm}$ in diameter in plate-plate geometry with a $2-\mathrm{mm}$ gap between the plates. After placing the fermented dough on the lower plate, the upper plate was lowered, and the excess dough was trimmed from the sample. The exposed surface was covered with a thin layer of petroleum jelly to prevent moisture loss during the testing. For the oscillatory test, frequency sweeps were performed at a strain of $0.1 \%$ in the linear region (part of the plot stress $v s$ strain where is lineal) at $25^{\circ} \mathrm{C}$ (Silvas-García et al., 2014). The dough's viscoelasticity was evaluated as the storage modulus $\left(G^{\prime}\right)$ and the loss modulus (G") at a frequency range from 0.1 to $10 \mathrm{rad} / \mathrm{s}$. The values were calculated using RSI Orchestrator software (Rheometric Scientific) (Magaña-Barajas et al., 2009). The tests were performed in duplicate.

\subsection{Bread preparation}

To make French-type bread, frozen dough samples were thawed and fermented for $50 \mathrm{~min}$. Then, the dough was baked in an electric oven (Partlow, National MFG, Lincoln, NE, USA) at $250{ }^{\circ} \mathrm{C}$ for 10 minutes. Bread loaves were cooled for 2 hours at $25^{\circ} \mathrm{C}$.

\subsection{Bread evaluation}

Specific volume

This parameter was determined in fresh bread ( $2 \mathrm{~h}$ after baking) by measuring the volume according to the rapeseed displacement method (National MFG Co. PUP, Lincoln, NE, USA) and the weight of the loaf. The specific volume was the ratio of the bread volume and weight (10-09 American Association of Cereal Chemists, 2000). The tests were performed in triplicate. 


\section{Texture Profile Analysis (TPA)}

The texture of bread was evaluated at 2, 24 and 48 hours after baking using the texture profile analysis (TPA). The crumb was prepared by cutting cubes ( $10 \mathrm{~mm}$ for each side) from the center of the loaf with an electric knife, and the firmness was analyzed in a texture analyzer (Stable Micro System TA.TXplus Texture Analyzer) with $40 \%$ double compression, a pretest speed of $1 \mathrm{~mm} / \mathrm{s}$, a test speed of $3 \mathrm{~mm} / \mathrm{s}$, a post-test speed of $5 \mathrm{~mm} / \mathrm{s}$ and a $25-\mathrm{mm}$ lapped Perspex cylinder probe. The test time was $5 \mathrm{~s}$. The tests were performed in triplicate.

\subsection{Experimental design and statistical analysis}

A $2 \times 3 \times 4$ factorial design was used. The factors and levels were as follow: freezing rate (fast, $-1.75^{\circ} \mathrm{C} / \mathrm{min}$, or slow, $-0.14^{\circ} \mathrm{C} / \mathrm{min}$ ), trehalose concentration ( 0,400 or $800 \mathrm{ppm})$, and storage time $(0,14,28$ or 42 days). Analysis of variance (ANOVA) at a $95 \%$ confidence level was performed on all data. Tukey's test was carried out to determine significant differences among specific treatments. Statistical analyses were conducted using Statistical Analysis Software (Statistical Analysis System, 2002).

\section{Results and discussion}

\subsection{Flour characterization}

Table 1 shows the characteristics of the wheat flour used. The overall quality of flour was acceptable for bread-making. It is generally recommended to use flour with a high protein content.

\subsection{Dough evaluation}

\section{Fermentative test}

ANOVA showed that all treatments had a significant $(\mathrm{P}<0.01)$ effect on $\mathrm{CO}_{2}$ production. The factors that had the greatest effect were storage time and the freezing rate of the dough. Figure 1 shows the effect of the freezing rate of the dough and the storage time on $\mathrm{CO}_{2}$ production. $\mathrm{CO}_{2}$ retention had the same trend (data not shown). At any storage time, except day 0 , dough frozen at

Table 1. Physicochemical and rheological characteristics of the tested wheat flour.

\begin{tabular}{lc}
\hline \multicolumn{1}{c}{ Characteristic } & Mean \\
\hline Chemical Analysis & \\
Moisture (\%) & $13.11 \pm 0.12^{2}$ \\
Ash content $^{1}(\%)$ & $0.45 \pm 0.02$ \\
${\text { Protein } \text { content }^{1}(\%)}(1.14 \pm 0.18$ \\
Sedimentation $^{1}(\mathrm{~mL})$ & $27.83 \pm 0.29$ \\
Wet gluten (\%) $^{\text {pH }}$ & $30.64 \pm 0.58$ \\
Farinograms & $6.85 \pm 0.02$ \\
Water absorption (\%) & \\
Stability (min) & $60 \pm 0.21$ \\
Development time (min) & $15.42 \pm 0.33$ \\
Alveograms & $6.92 \pm 0.29$ \\
Deformation energy (W) (J) & \\
Curve configuration ratio (P/L) (mm) & $0.83 \pm 0.03$ \\
\hline
\end{tabular}

${ }^{1}$ Dry basis. ${ }^{2}$ Standard deviation. the slow rate $\left(-0.14^{\circ} \mathrm{C} / \mathrm{min}\right)$ evidenced higher $\mathrm{CO}_{2}$ production than dough frozen quickly $\left(-1.75^{\circ} \mathrm{C} / \mathrm{min}\right)$. However, regardless of the freezing rate, the $\mathrm{CO}_{2}$ production decreased with storage time. This result is consistent with Giannou et al. (2005), who noted that a fast freezing rate is more harmful to the yeast because it causes mechanical breakage of the cell membranes by a conglomeration of small crystals, which in turn leads to a loss of cell viability and therefore lower $\mathrm{CO}_{2}$ production. Conversely, some studies have suggested that a fast freezing rate forms smaller ice crystals in the dough that cause less damage to disulfide bonds (S-S), allowing the dough to produce more gas. However, more yeast are damaged in dough frozen at a fast freezing rate, resulting in greater cell death; therefore, more glutathione is released, which affects the gluten network by reducing S-S to sulfhydryl groups (-SH) and decreasing the amount of gas retention.

Figure 2 shows the effect of the trehalose concentration and storage time on $\mathrm{CO}_{2}$ production. Regardless of the trehalose concentration, $\mathrm{CO}_{2}$ production decreased with storage time. During the first 14 days of storage, there was no indication of

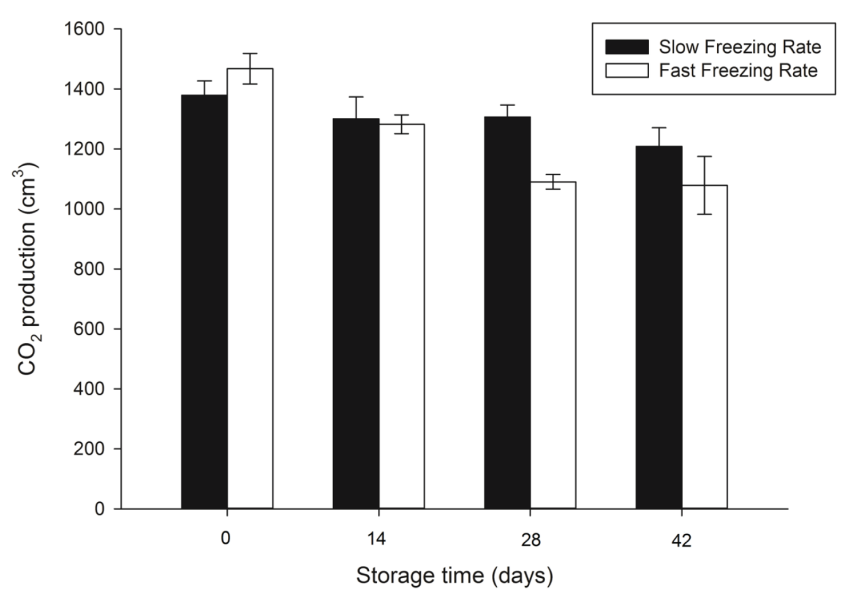

Figure 1. Effect of the freezing rate and storage time on $\mathrm{CO}_{2}$ production in frozen dough.

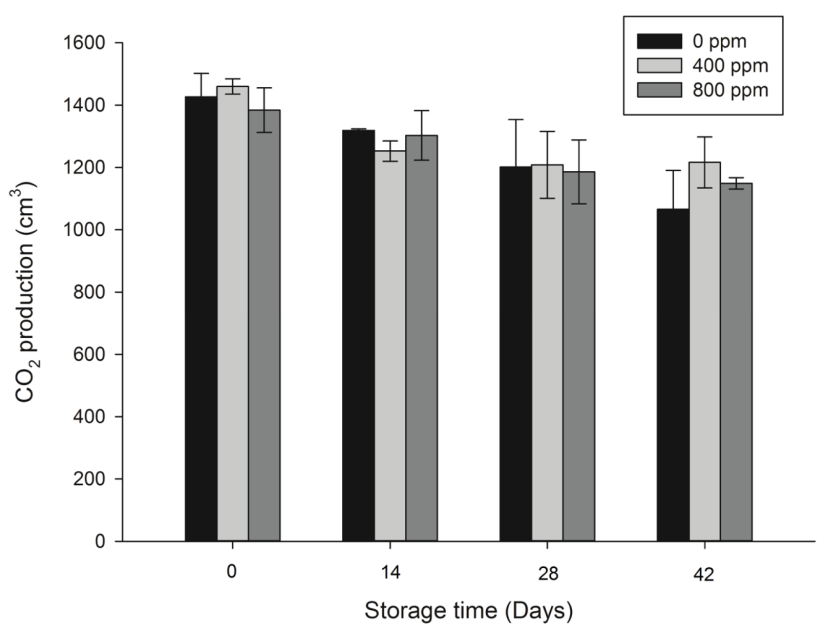

Figure 2. Effect of the trehalose concentration and storage time on $\mathrm{CO}_{2}$ production in frozen dough. 
an optimal trehalose concentration. However, after 14 days storage, a trehalose concentration of 400 ppm gave higher $\mathrm{CO}_{2}$ production than 0 and $800 \mathrm{ppm}$ of trehalose. The results of this research are consistent with the results reported by Giannou \& Tzia (2007) and Sasano et al. (2012).

\section{Viscoelasticity evaluation}

ANOVA showed that the freezing rate of the dough and the storage time were the factors that most significantly $(\mathrm{P}<0.01)$ affected the dough's viscoelasticity. Figure 3 shows the effect of the dough's freezing rate and the storage time on the dough's elastic modulus ( $\left.G^{\prime}\right)$. Regardless of the freezing rate, there was an increase in $\mathrm{G}^{\prime}$ with storage time. Dough frozen at a slow rate $\left(-0.14{ }^{\circ} \mathrm{C} / \mathrm{min}\right)$ showed better results because the dough's elasticity was better retained than in the dough frozen at a fast rate $\left(-1.75^{\circ} \mathrm{C} / \mathrm{min}\right)$ at all storage times evaluated and at a frequency of $5 \mathrm{rad} / \mathrm{s}$ (linear region). The dough frozen at a fast freezing rate showed the same trend in G', which means that a more rigid dough forms over time and a greater effort must be exerted to deform the dough. Therefore, the gluten network is more damaged during storage likely because of water recrystallization in the dough. This results in a decrease in gluten elasticity due to HMW glutenin depolymerization, which is caused by a decrease in the disulfide bonds (Meziani et al., 2011). The values of G' were higher at the fast freezing rate, indicating that more stress is required to deform the dough due to a reduction in disulfide bonds caused by the release of glutathione by damaged yeast.

Figure 4 shows the effect of the freezing rate and storage time on the viscous contribution (G") of dough. The G" values increased with storage time at both freezing rates, but the fast freezing rate $\left(-1.75^{\circ} \mathrm{C} / \mathrm{min}\right)$ resulted in the greatest increase at all storage times evaluated at a frequency of $5 \mathrm{rad} / \mathrm{s}$ (linear region). The change in the G'/G' proportion, also named tan $\delta$, is the reason for a more viscous than elastic dough resulting from longer storage.

\subsection{Bread analysis}

\section{Specific volume}

ANOVA showed that the freezing rate of the dough and the trehalose concentration significantly $(\mathrm{P}<0.01)$ affected the bread volume. Figure 5 shows the effect of the trehalose concentration and the dough's freezing rate. Dough frozen slowly and containing $400 \mathrm{ppm}$ and $800 \mathrm{ppm}$ trehalose showed the highest specific volume, and these results followed the same trend for all storage times (data not shown). These results are probably due to higher cell viability at a slow freezing rate $\left(-0.14^{\circ} \mathrm{C} / \mathrm{min}\right)$, which allowed more $\mathrm{CO}_{2}$ production. Trehalose had a cryoprotectant effect in yeast, inhibiting the decrease in cell viability. According to Haines (2003), trehalose interacts with the cell membrane, protects it from environmental stress, and absorbs water, thereby decreasing water diffusion and protein damage.

\section{Crumb firmness}

This parameter was obtained from the texture profile analysis (TPA) and is representative of bread quality $(\mathrm{P}<0.01)$. According to ANOVA, the factors that had the greatest effect on crumb firmness

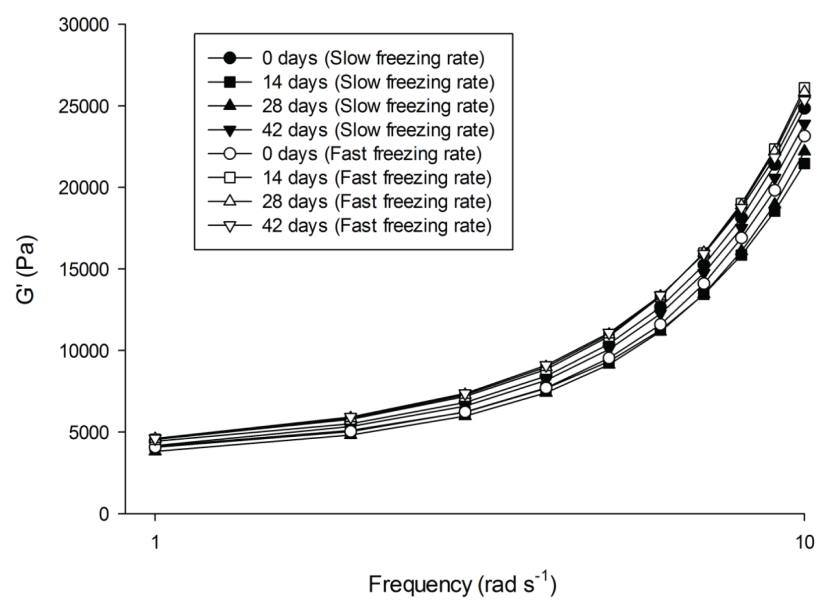

Figure 3. Effect of the freezing rate and storage time on the elastic modulus (G').

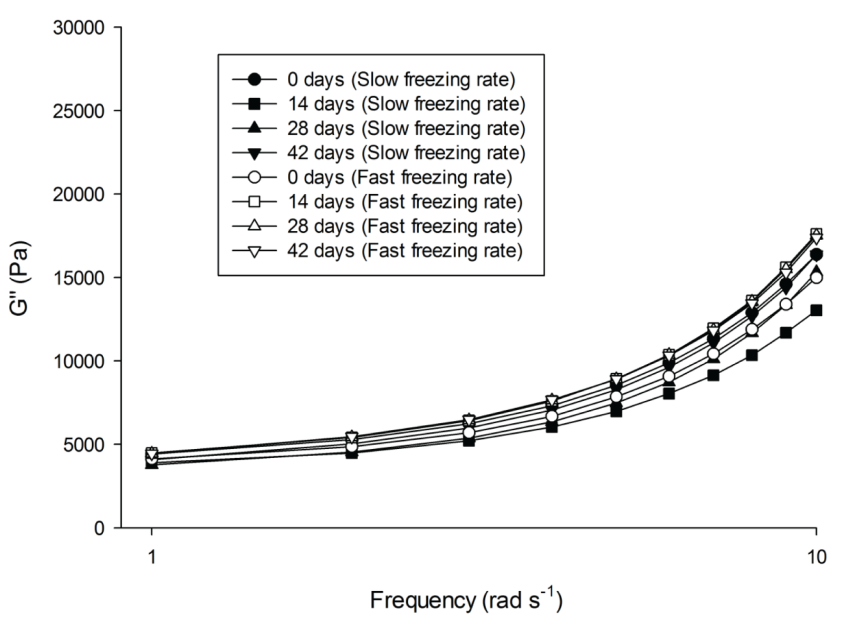

Figure 4. Effect of the freezing rate and storage time on the viscous modulus (G").

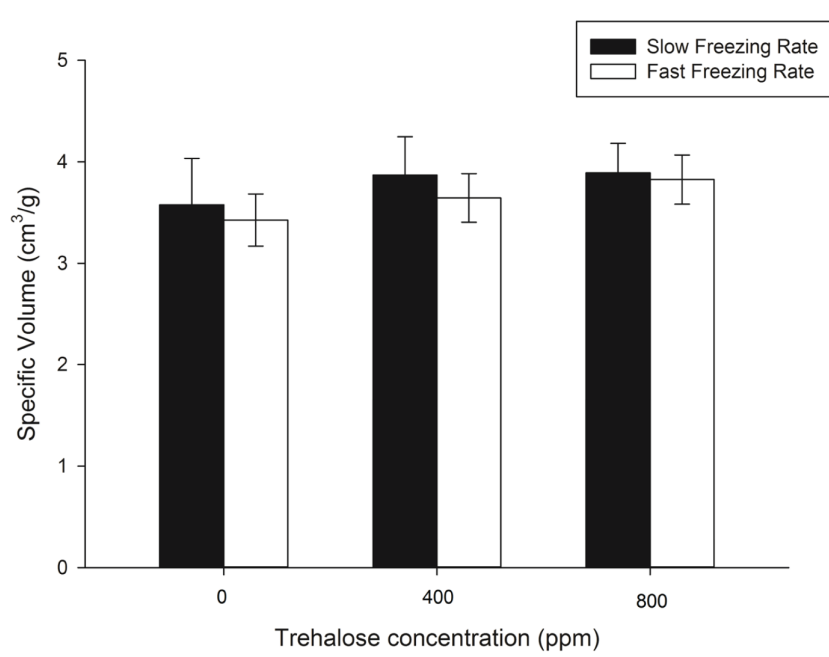

Figure 5. Effect of the freezing rate and trehalose concentration on the specific volume of bread. 
Table 2. Effect of trehalose concentration and storage time on the bread crumb firmness (g-f).

\begin{tabular}{crrr}
\hline \multirow{2}{*}{ Days } & \multicolumn{1}{c}{ TC $^{1}$} \\
\cline { 2 - 4 } & \multicolumn{1}{c}{0 ppm } & \multicolumn{1}{c}{$400 \mathrm{ppm}$} & $800 \mathrm{ppm}$ \\
\hline 0 & $958.93 \pm 182.15^{2}$ & $989.21 \pm 223.33$ & $964.08 \pm 137.13$ \\
14 & $1663.58 \pm 297.68$ & $1484.58 \pm 177.78$ & $1226.33 \pm 194.53$ \\
28 & $1847.43 \pm 323.05$ & $1417.21 \pm 201.96$ & $1157.00 \pm 123.45$ \\
42 & $1893.60 \pm 382.56$ & $1258.50 \pm 212.88$ & $1314.41 \pm 169.47$ \\
\hline
\end{tabular}

${ }^{1}$ TC, Trehalose Concentration. ${ }^{2}$ Standard Deviation.

were the storage time and the trehalose concentration $(\mathrm{P}<0.01)$. Table 2 shows the effect of the trehalose concentration and the storage time. The greatest increase in bread firmness occurred during the period from 0 to 14 days of storage. From 14 to 42 days, bread firmness was the highest at any trehalose concentration, and the values remained similar. However, regardless of the storage time (except for day 0), bread firmness decreased at trehalose concentrations of $400 \mathrm{ppm}$ and $800 \mathrm{ppm}$. The addition of $800 \mathrm{ppm}$ trehalose gave approximately the same and lowest bread firmness at storage times of 28 and 42 days. Our results agree with those reported by Giannou \& Tzia (2007). A possible cause of the increase in firmness when dough is frozen is water loss; after a freeze-thaw cycle, the water that was previously bound to proteins and starch does not return to its place of origin. Trehalose absorbs water and prevents diffusion (Bar, 2000). Frozen storage had a negative effect on crumb firmness, and larger crystals were formed due to recrystallization, which led to further water loss in the thawing dough.

\section{Conclusions}

An optimal combination of the freezing rate of dough, the trehalose concentration and storage time improved the fermentative properties of the dough and the bread quality, allowing the production of a product comparable to fresh bread. A slow freezing rate caused less damage to the yeast and gluten network; better results were obtained for all measurements, including fermentation tests, rheological properties and texture. Long storage times at freezing temperatures decreased the fermentative and rheological properties of the dough as well as the bread's textural qualities, resulting in lower loaf volume and increased crumb firmness, but these parameters improved with the addition of trehalose. A slow freezing rate, $800 \mathrm{ppm}$ trehalose and 42 days of storage at $-20^{\circ} \mathrm{C}$ constituted the best combination to produce quality bread from frozen dough. The results obtained in this research indicate that a slow freezing rate should be used in the presence of yeast.

\section{Acknowledgements}

This study is part of Grant No. 154090 from CONACyT, "Study of Water Re-distribution in Gluten from Frozen Dough, and its Effect on Protein and Viscoelasticity Changes". The authors thank Hayashibara Co., Ltd., Okayama, Japan for providing the trehalose.

\section{References}

American Association of Cereal Chemists - AACC. (2000). Approved methods of the American Association of Cereal Chemists (10th ed.). Saint Paul: AACC. Methods (02-52, 08-30, 10-09, 38-11, 44-40, 46-13, 54-10, 54-21, 54-30, 56-61A).
Anon, M. C., Lebail, A., \& Leon, A. E. (2004). Effect of freezing on dough ingredients. In Y. H. Hui, P. Cornillon, I. G. Legaretta, M. H. Lim, K. D. Murrell \& W-K. Nip (Eds.), Handbook of frozen foods. New York: Marcel Dekker.

Bar, A. (2000). Trehalose-produced by a novel enzymatic process. London: Advisory Committee on Novel Foods and Processes. Dossier prepared and submitted on behalf of Hayashibara Co., Ltd., for evaluation pursuant to the EU Novel Foods Regulation (258/97).

Casey, G. P., \& Foy, J. J. (1995). Yeast performance in frozen doughs and strategies for improvement. In K. Kulp, K. Lorenz \& J. Brümmer (Eds.), Frozen and refrigerated doughs and batters. Minnesota: American Association of Cereal Chemists.

Cho, I. H., \& Peterson, D. G. (2010). Chemistry of bread aroma: a review. Food Science and Biotechnology, 19(3), 575-582. http://dx.doi. org/10.1007/s10068-010-0081-3.

Diniz-Mendes, L., Bernardes, E., de Araujo, P. S., Panek, A. D., \& Paschoalin, V. M. (1999). Preservation of frozen yeast cells by trehalose. Biotechnology and Bioengineering, 65(5), 572-578. http:// dx.doi.org/10.1002/(SICI)1097-0290(19991205)65:5<572::AIDBIT10>3.0.CO;2-7. PMid:10516583.

Fuchigami, M., Ogawa, N., \& Teramoto, A. (2002). Trehalose and hydrostatic pressure effects on the structure and sensory properties of frozen tofu soybean curd. Innovative Food Science \& Emerging Technologies, 3(2), 139-147. http://dx.doi.org/10.1016/S14668564(02)00007-3.

Gant, Z., Angold, R. E., Wiliams, M. R., Ellis, P. R., Vaughan, J. G., \& Galliard, T. (1990). The microstructure and gas retention of bread dough. Journal of Cereal Science, 12(1), 15-24. http://dx.doi. org/10.1016/S0733-5210(09)80153-7.

Giannou, V., \& Tzia, C. (2007). Crioprotective rol of exogenous trehalose in frozen dough products. Food Bioprocess Technol, 1(3), 276-284. http://dx.doi.org/10.1007/s11947-007-0008-z.

Giannou, V., Tzia, C., \& Lebail, A. (2005). Quality and safety of frozen bakery products. In D-W. Sun (Ed.), Handbook of frozen food processing and packaging. New York: Marcel Dekker.

Haines, A. H. (2003). Synthesis of L-trehalose and observations on isomer and by-product formation. Carbohydrate Research, 338(9), 813-818. http://dx.doi.org/10.1016/S0008-6215(03)00043-0. PMid:12681904.

Karel, M., \& Lund, D. B. (2003). Freezing. In M. Karel, O. R. Fennema \& D. B. Lund (Eds.), Physical principles of food preservation. New York: Marcel Dekker.

Magaña-Barajas, E., Ramírez-Wong, B., Platt-Lucero, L., López-Ahumada, G., Torres, P., \& Sánchez-Machado, D. (2009). Caracterización viscoelástica de masas de variedades de trigos suaves. Tecnología, Ciencia. La Educación, 24, 12-22.

Meziani, S., Jasniewski, J., Gaiani, C., Ioannou, I., Muller, J., Ghoul, M., \& Desobry, S. (2011). Effects of freezing treatments on viscoelastic and structural behavior of frozen sweet dough. Journal of Food Engineering, 107(3-4), 358-365. http://dx.doi.org/10.1016/j.jfoodeng.2011.07.003. 
Ribotta, P. D., Perez, G. T., Leon, A. E., \& Anon, M. C. (2004). Effect of emulsifier and guar gum on micro structural, rheological and baking performance of frozen bread dough. Food Hydrocolloids, 18(2), 305-313. http://dx.doi.org/10.1016/S0268-005X(03)00086-9.

Rouille, J., Lebail, A., \& Courcoux, P. (2000). Influence of formulation and mixing conditions on bread making qualities of French frozen dough. Journal of Food Engineering, 43(4), 197-203. http://dx.doi. org/10.1016/S0260-8774(99)00148-X.

Sasano, Y., Haitani, Y., Hashida, K., Ohtsu, I., Shima, J., \& Takagi, H. (2012). Simultaneous accumulation of proline and trehalose in industrial baker's yeast enhances fermentation ability in frozen dough. Journal of Bioscience and Bioengineering, 113(5), 592-595. http://dx.doi.org/10.1016/j.jbiosc.2011.12.018. PMid:22280966.
Selomulyo, V. O., \& Zhou, W. (2007). Frozen bread dough: effects of freezing storage and dough improvers. Journal of Cereal Science, 45(1), 1-17. http://dx.doi.org/10.1016/j.jcs.2006.10.003.

Silvas-García, M. I., Ramírez-Wong, B., Torres-Chávez, P. I., CarvajalMillan, E., Barrón-Hoyos, J. M., Bello-Pérez, L. A., \& Quintero-Ramos, A. (2014). Effect of freezing rate and storage time on gluten protein solubility, and dough and bread properties. Journal of Food Process Engineering, 37(3), 237-247. http://dx.doi.org/10.1111/jfpe.12079.

Statistical Analysis System - SAS. (2002). SAS: users guide. Cary: SAS Institute.

Tanghe, A., Teunissen, A., Van Dijck, P., \& Thevelein, J. M. (2000). Identification of genes responsible for improved cryoresistance in fermenting yeast cells. International Journal of Food Microbiology, 55(1-3), 259-262. http://dx.doi.org/10.1016/S0168-1605(00)002002. PMid:10791754. 